\title{
7T Brain MRS in HIV Infection: Correlation with Cognitive Impairment and Performance on Neuropsychological Tests
}

\author{
(D) M. Mohamed, DP.B. Barker, DR.L. Skolasky, and DN. Sacktor
}

\begin{abstract}
BACKGROUND AND PURPOSE: Validated neuroimaging markers of HIV-associated neurocognitive disorder in patients on antiretroviral therapy are urgently needed for clinical trials. The purpose of this study was to explore the relationship between cognitive impairment and brain metabolism in older subjects with HIV infection. It was hypothesized that MR spectroscopy measurements related to neuronal health and function (particularly $\mathrm{N}$-acetylaspartate and glutamate) would be lower in HIV-positive subjects with worse cognitive performance.
\end{abstract}

MATERIALS AND METHODS: Forty-five HIV-positive patients (mean age, $58.9 \pm 5.3$ years; 33 men) underwent detailed neuropsychological testing and brain MR spectroscopy at 7T. Twenty-four subjects were classified as having asymptomatic cognitive impairment, and 21 were classified as having symptomatic cognitive impairment. Single-voxel proton MR spectra were acquired from 5 brain regions and quantified using LCModel software. Brain metabolites and neuropsychological test results were compared using nonparametric statistics and Pearson correlation coefficients.

RESULTS: Differences in brain metabolites were found between symptomatic and asymptomatic subjects, with the main findings being lower measures of $\mathrm{N}$-acetylaspartate in the frontal white matter, posterior cingulate cortex, and precuneus. In the precuneus, glutamate was also lower in the symptomatic group. In the frontal white matter, precuneus, and posterior cingulate cortex, NAA and glutamate measurements showed significant positive correlation with better performance on neuropsychological tests.

CONCLUSIONS: Compared with asymptomatic subjects, symptomatic HIV-positive subjects had lower levels of NAA and glutamate, most notably in the frontal white matter, which also correlated with performance on neuropsychological tests. High-field MR spectroscopy offers insight into the pathophysiology associated with cognitive impairment in HIV and may be useful as a quantitative outcome measure in future treatment trials.

ABBREVIATIONS: CART = combined antiretroviral therapy; $\mathrm{FWM}=$ frontal white matter; $\mathrm{Glu}=$ glutamate; $\mathrm{HAND}=\mathrm{HIV}$-associated neurocognitive disorder $\mathrm{PC}=$ precuneus; $\mathrm{PCC}=$ posterior cingulate cortex; $\mathrm{tNAA}=\mathrm{NAA}+\mathrm{N}$-acetyl aspartylglutamate

$\mathrm{H}^{2}$ uman immunodeficiency virus-associated neurocognitive disorder (HAND) is characterized by cognitive, behavioral, and motor dysfunction, which impacts daily functioning ${ }^{1-3}$ and is predictive of poor survival in patients. ${ }^{4}$ Combination antiretrovi-

Received August 3, 2017; accepted after revision December 1.

From the Russell H. Morgan Department of Radiology and Radiological Science (M.M., P.B.B.) and Departments of Neurology (R.L.S., N.S.), Orthopedic Surgery (R.L.S.), and Psychiatry and Behavioral Sciences (P.B.B.), Johns Hopkins University School of Medicine, Baltimore, Maryland; and F.M. Kirby Center for Functional Brain Imaging (P.B.B.), Kennedy Krieger Institute, Baltimore, Maryland.

This work was funded by National Institutes of Health grants RO1NS081196, P41EB015909, and P30MH075673.

Please address correspondence to Mona A. Mohamed, MD, Department of Radiology, Johns Hopkins University School of Medicine, 600 N Wolfe St, Park Building, Third Floor, 367G, Baltimore, MD 21287; e-mail: mnourel1@jhmi.edu

-- Indicates open access to non-subscribers at www.ajnr.org

三 Indicates article with supplemental on-line table.

http://dx.doi.org/10.3174/ajnr.A5547 ral therapy (cART) can improve cognitive performance and brain metabolism in some patients with HAND. ${ }^{2,5,6}$ However, many antiretroviral drugs do not penetrate well into the central nervous system, ${ }^{7}$ and neurocognitive deficits are reversed in many but not all patients. ${ }^{8,9}$ The prevalence of HAND in HIV positive (HIV+) individuals with advanced infection remains around 45\%-50\%, and patients are now surviving for years with HIV infection and HAND as chronic conditions. ${ }^{10,11}$ Advanced age is an important risk factor for HAND; for instance, in the Hawaii Aging with HIV cohort, HIV + individuals older than 50 years of age were twice as likely to have dementia compared with HIV + individuals who were 20-39 years of age. ${ }^{12,13}$ Because HIV + individuals are now living longer as a result of cART, the proportion of HIV + individuals older than 50 years of age has increased.

There is some evidence that HIV + subjects may develop cognitive decline earlier than the HIV-negative (HIV-) population (ie, more rapid aging). For the quantitative assessment of neuro- 


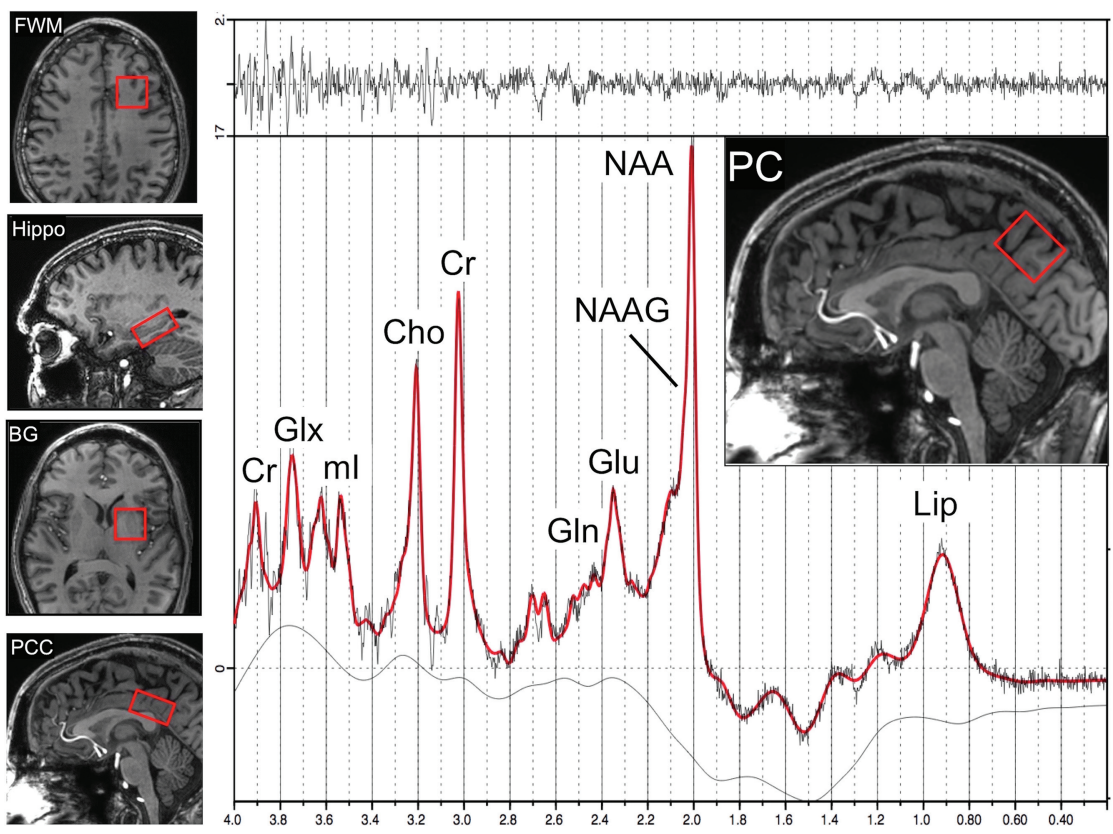

FIG 1. Examples of the 5 voxel locations used for brain MR spectroscopy in the left frontal white matter, left hippocampus (Hippo), left basal ganglia (BG), mesial posterior cingulate cortex, and mesial precuneus. An example of a spectrum from the PC in a 55-year-old HIV + subject is shown, including results from the LCModel analysis (red curve). Signals are assigned to lipids (Lip), Nacetylaspartate, $\mathrm{N}$-acetyl aspartylglutamate (NAAG), glutamate, glutamine (Gln), creatine, choline, myoinositol (ml), and Glx (the sum of Glu and Gln). The top trace is the difference between the original data and the results of the curve fit.

logic involvement in older HIV + individuals, it is important to develop and validate noninvasive imaging tools that are sensitive to changes in cognitive and behavioral statuses, which, for instance, may be of use as quantitative measures in future treatment trials. Measurements of regional brain metabolism may also shed some light on the neurobiology of brain aging and cognitive decline in the older HIV+ population.

Proton MR spectroscopy (MR spectroscopy) is a noninvasive technique that gives information on brain pathophysiology through measurement of brain metabolite levels. ${ }^{14}$ The most common observations in HIV+ subjects are increased levels of choline ${ }^{15}$ and mIns, ${ }^{16}$ thought to reflect inflammation and microglial proliferation, and decreased levels of $N$-acetylaspartate and glutamate, ${ }^{17-19}$ believed to be due to neuronal injury or dysfunction. ${ }^{15,20-22}$ Metabolic abnormalities may be observed in regions of the brain with normal appearance on conventional MR imaging, even in subjects who are neurologically asymptomatic, and increase with increasing degrees of neurologic involvement. ${ }^{23}$ Thus, MR spectroscopy has been proposed as suitable tool for monitoring the degree of HIV involvement in the brain and the effects of therapy. ${ }^{24,25}$

MR spectroscopy at field strengths of $1.5 \mathrm{~T}, 3 \mathrm{~T}$, and $4 \mathrm{~T}^{6,18,26-28}$ has been extensively used to investigate neurologic involvement in HIV + subjects. Higher magnetic field strengths (such as 7T) allow increased sensitivity and chemical shift dispersion and more reliable determination of brain metabolites, particularly for some of the smaller and overlapping signals in the spectrum, such as glutamate and glutamine. ${ }^{29,30}$

The current study was undertaken to investigate the utility of 7T MR spectroscopy in evaluating a cohort of older HIV+ pa- tients with varying degrees of neurocognitive impairment. It was hypothesized that differences in brain metabolites reflecting neuronal and glial cell populations would be observed between older $\mathrm{HIV}+$ individuals with and without cognitive impairment. For analysis, patients were classified either as "asymptomatic" (ie, either cognitively healthy or having asymptomatic neurocognitive impairment) or "symptomatic" (HAND, including those with either a mild neurocognitive disorder or HIVassociated dementia).

\section{MATERIALS AND METHODS Participants and Clinical Testing}

The study was approved the local institutional review board, and all subjects gave written informed consent. HIV+ individuals were recruited at the Institute for Clinical and Translational Research at Johns Hopkins Hospital in Baltimore, Maryland, from 2013 to 2016. Inclusion criteria were adults who were HIV-positive, older than 50 years of age, and had the ability to provide written informed consent and to ambulate at the first clinic visit. Patients were excluded if they had a history of or current opportunistic central nervous system infection, schizophrenia, affective disorder, or psychiatric diseases, which could be a confounder for cognitive impairment, or chronic neurologic disorders such as brain infarction, hemorrhage, epilepsy, and multiple sclerosis. Active substance abusers or opiate users were excluded, defined as any history of illicit drug use within 3 months preceding the baseline visit, established by subject history and urine toxicology screens. Any contraindication for 7T MR imaging (metal in the body, claustrophobia, inner ear disorder) was also an exclusion criterion.

As described above, subjects were stratified by neurocognitive disorder status using the revised American Academy of Neurology "Frascati" criteria. ${ }^{31}$ All subjects underwent detailed neurologic, neuropsychological, laboratory, and functional assessments. Clinical assessments included standardized questionnaires that assessed demographic information, including primary language; reading abilities; medical, psychiatric, and neurologic history; and a neurologic examination. Serum CD4 T-cell counts and HIV RNA levels via quantitative polymerase chain reaction in the plasma and CSF were obtained. Depression symptomatology was rated using the Center for Epidemiological Studies Depression Scale. ${ }^{32}$ Hepatitis C viral status was obtained via clinical history and evaluation of laboratory findings for hepatitis $\mathrm{C}$ virus antibodies.

Measures of functional performance included the Karnofsky Performance Scale, a questionnaire for instrumental activities of daily living, and a questionnaire for physical quality of life measures. ${ }^{1-3,33-35}$ Neuropsychological testing included the Trail- 
Making Test, Color Trails Test, Grooved Pegboard Test, Digit Symbol Test, Stroop Test, Rey Complex Figure Test, and Hopkins Verbal Learning Test. ${ }^{36-38}$ Raw scores on each neuropsychological test were converted to $z$ scores using published normative data. $^{31}$

\section{MR Imaging and Spectroscopy}

All studies were performed on a 7T scanner (Achieva; Philips Healthcare, Best, the Netherlands) equipped with a 32-channel receive head coil and quadrature transmit coil (Nova Medical, Wilmington, Massachusetts). Brain MR imaging consisted of lo-

\begin{tabular}{|c|c|c|c|}
\hline & ANI & HAND & $P$ Value \\
\hline No. & 24 & 21 & - \\
\hline Age $(y r)$ & $59.6 \pm 5.7$ & $58.2 \pm 5.0$ & .378 \\
\hline Male sex (No.) (\%) & $17(71 \%)$ & $16(76 \%)$ & .764 \\
\hline Education (yr) & $14.9 \pm 3.0$ & $14.0 \pm 2.7$ & .263 \\
\hline Race (\% African American) & $12(50 \%)$ & $13(62 \%)$ & .655 \\
\hline Duration of infection (yr) & $19.9 \pm 9.0$ & $19.2 \pm 9.4$ & .790 \\
\hline CES-D & $7.7 \pm 6.8$ & $11.0 \pm 11.7$ & .253 \\
\hline HART Est IQ & $112.9 \pm 12.8$ & $103.7 \pm 12.9$ & .022 \\
\hline CD4 cell count (cells/mm³) & $674 \pm 281$ & $676 \pm 375$ & .988 \\
\hline Plasma HIV RNA $\left(\log ^{10}\right.$ copies/mL) & $1.6 \pm 0.1$ & $2.3 \pm 1.4$ & .569 \\
\hline
\end{tabular}

Note:-ANI indicates asymptomatic neurocognitive impairment; $C E S-D=$ Center for Epidemiological Studies Depression Scale; HART Est IQ = Hopkins Adult Reading Test estimated intelligence quotient.

${ }^{a}$ Values given are mean \pm SD unless otherwise indicated.

b Significant $(P<.05)$.

c Plasma HIV RNA only among those with detectable viral load $(n=2 \mathrm{ANI}$ and $n=3$ HAND).
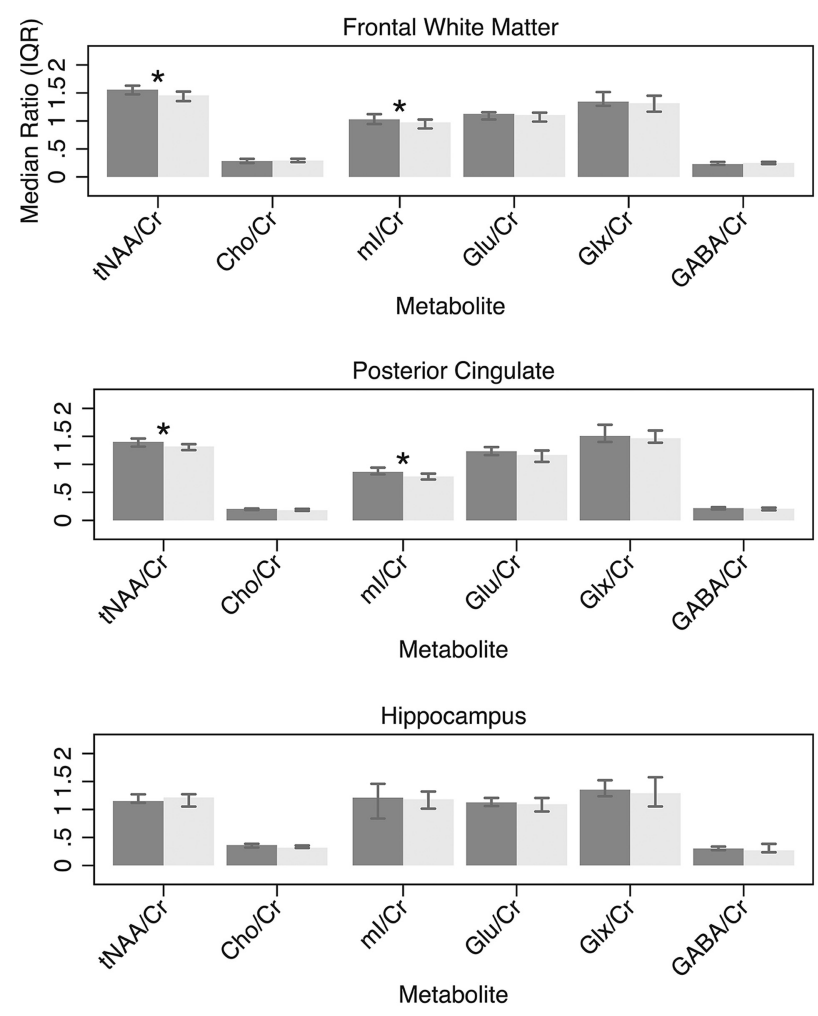

calizer images and a 3D T1-weighted MPRAGE scan with 1.2-mm isotropic voxel size. Single-voxel Stimulated Echo Acquisition Mode (STEAM) spectra (TR/TE/mixing time $=3000 / 14 / 25 \mathrm{~ms}$ ) were acquired from the left frontal white matter (FWM), left basal ganglia, mesial precuneus (PC), mesial posterior cingulate cortex (PCC), and left hippocampus with and without variable power and optimized relaxation water suppression. These regions were chosen on the basis of prior studies that have indicated that the regions are involved in HIV infection and aging. ${ }^{10,39-41}$ The voxel sizes ranged from 8 to $15 \mathrm{~mL}$ (Fig 1). The hippocampal voxel was carefully angulated parallel to the long axis of the hippocampus and had dimensions of $1.5 \times 1.5 \times 3.5 \mathrm{~cm}$ to minimize partial volume contributions from surrounding tissues. Eighty acquisitions had water suppression, and 2 were unsuppressed, to give a total scan time per region of 4 minutes 6 seconds. Before the acquisition of each region, field inhomogeneity was corrected up to second order using the FASTMAP (fast, automatic shimming technique by mapping along projections) localized shimming technique, ${ }^{42}$ and localized power optimization ${ }^{43}$ was also performed (transmit $\mathrm{B}_{1}=15 \mu \mathrm{T}$ ).

Spectra were analyzed using a basis set designed for the $7 \mathrm{~T}$ STEAM sequence incorporated in the LCModel software package (http://www.lcmodel.com/) ${ }^{44}$ and quantified in approximately millimolar concentrations (referred to here as institutional units because relaxation time corrections were not performed) relative to the unsuppressed water signal. Ratios relative to creatine were also calculated. We did not perform any volumetric morphome-
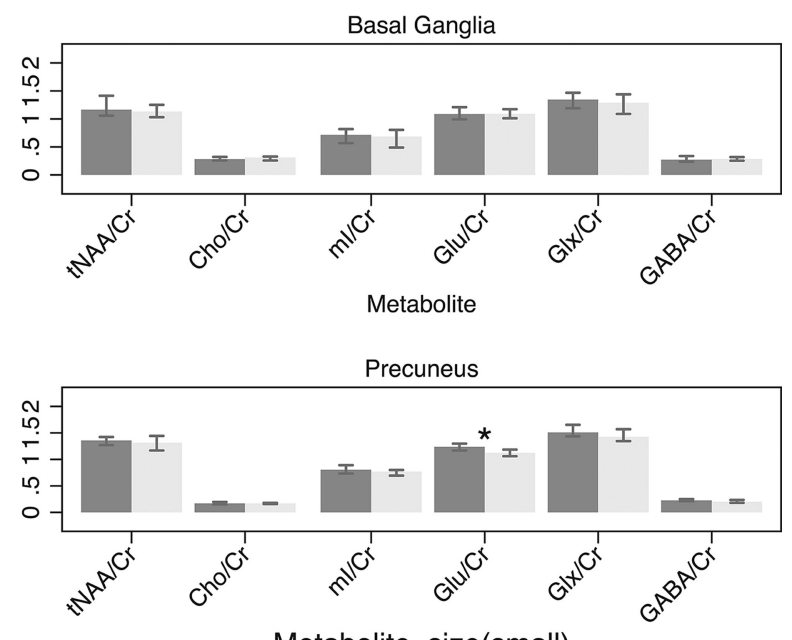

Metabolite, size(small)

\section{Asymptomatic}

\section{Symptomatic}

FIG 2. Metabolite ratios for the frontal white matter, posterior cingulate, precuneus, basal ganglia, and hippocampal voxels. Asterisk indicates significant; GABA, $\gamma$-aminobutyric acid; IQR, interquartile range; ml, myoinositol. 

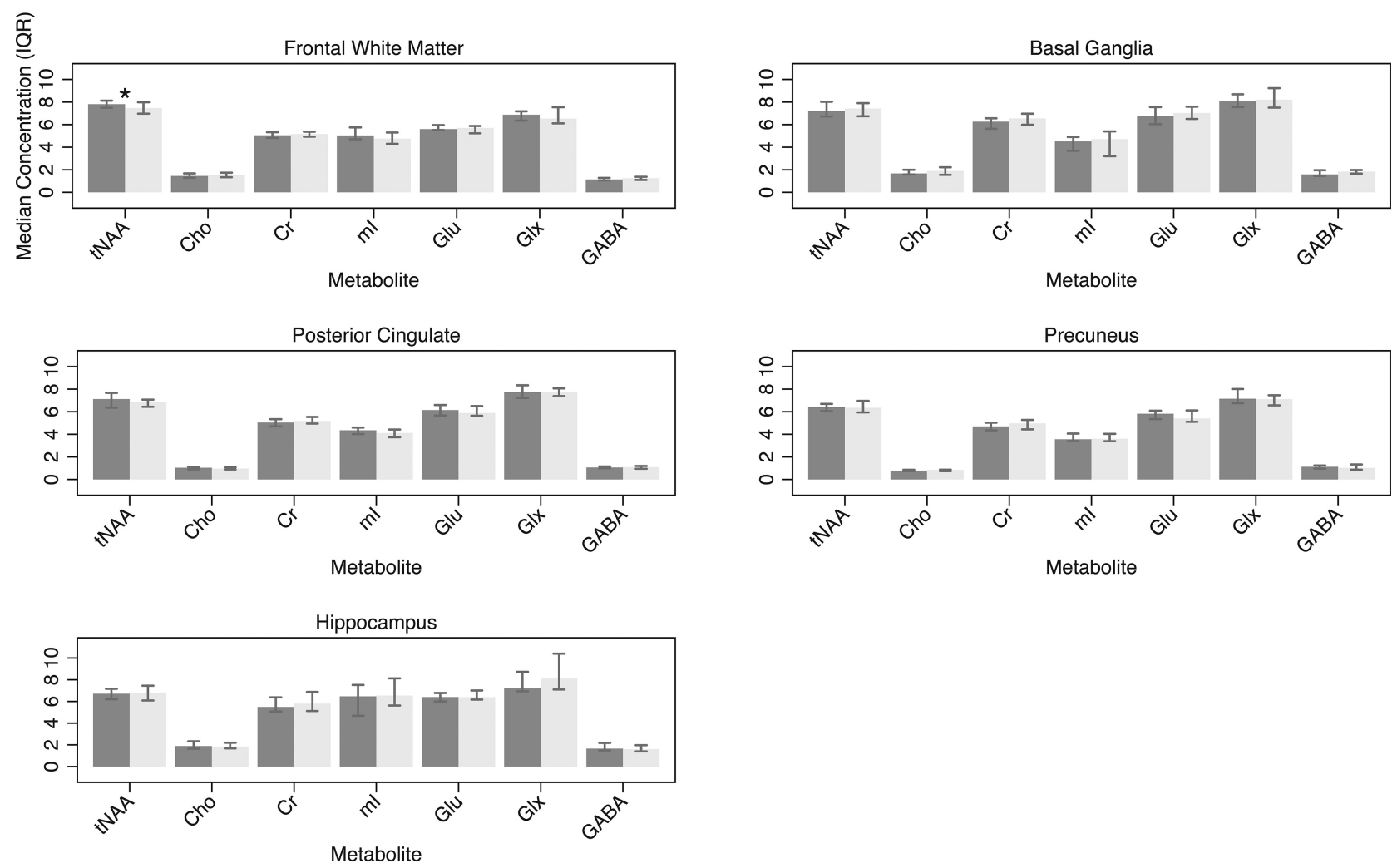

Asymptomatic

\section{Symptomatic}

FIG 3. Metabolite concentrations in institutional units for the frontal white matter, posterior cingulate, precuneus, basal ganglia, and hippocampal voxels. Asterisk indicates significant, GABA, $\gamma$-aminobutyric acid; IQR, interquartile range; ml, myoinositol.

try because we reported metabolite ratios in addition to metabolite concentrations. The LCModel basis set contained 20 different metabolites and the standard LCModel macromolecule peaks. Concentration and ratio values were only included for statistical analysis if their Cramér-Rao lower bounds were $\leq 20 \% .{ }^{44}$ A representative PC spectrum is shown from 1 subject in Fig 1.

\section{Statistical Analysis}

The objective of the current study was to compare metabolite concentration and ratio values between older HIV + patients who were either asymptomatic or symptomatic for neurocognitive impairment. With the Shapiro-Wilk test, the data were not normally distributed; therefore, we present the data as median and interquartile range (interquartile range, 25th and 75th percentiles). Between-group comparisons were made using the nonparametric median test. Pearson correlation coefficients were calculated between metabolite values and concentrations and neurocognitive tests.

\section{RESULTS}

Forty-five subjects (mean age, $58.9 \pm 5.3$ years; 33 [73\%] men) were enrolled. All patients were receiving cART. Twenty-four subjects were classified as asymptomatic, and 21, as symptomatic. Patient demographics are given in the Table. There were no significant group differences in age, education, sex, race, CD4 count, or plasma HIV RNA between groups. The estimated intelligence quotient was significantly lower in the symptomatic group (103.7 versus 112.9 , respectively, $P=.02$ ). Apart from some small white matter hyperintensities in 2 individuals, which were avoided during MR spectroscopy voxel placement, there were no significant T2WI or FLAIR lesions or other abnormalities in any of the subjects in this study.

In the frontal white matter, the median $\mathrm{NAA} / \mathrm{Cr}$ ratio was lower in the symptomatic group compared with the asymptomatic group (1.21 versus 1.30 , respectively; $P=.005)$, and NAA+ $\mathrm{N}$-acetyl aspartylglutamate (tNAA)/Cr (1.46 versus 1.56 , respectively; $P=.005)$ and the median $\mathrm{mIns} / \mathrm{Cr}$ (0.97 versus 1.03 , respectively; $P=.02$ ) (Fig 2). There was also a trend toward lower FWM tNAA concentration in the symptomatic group compared with the asymptomatic group (7.46 versus $7.81 \mathrm{mmol} / \mathrm{L}$, respectively; $P=.06$ ) (Fig 3). In the posterior cingulate cortex, the median NAA/Cr was also significantly lower in the symptomatic group ( 1.16 versus 1.21 , respectively; $P=.01$ ), as was the median tNAA/Cr (1.32 versus 1.40 , respectively; $P=.02)$ and median $\mathrm{mIns} / \mathrm{Cr}(0.78$ versus 0.87 , respectively; $P=.002)$ (Fig 2$)$. In the precuneus, the median NAA/Cr was also significantly lower in the symptomatic group ( 1.14 versus 1.23 , respectively; $P=.02$ ), as was median glutamate/Cr $(\mathrm{Glu} / \mathrm{Cr})$ (1.12 versus 1.24 , respectively; $P=.01$ ) (Fig 2). There were no significant differences between groups in basal ganglia and hippocampus metabolite concentrations or ratios. 

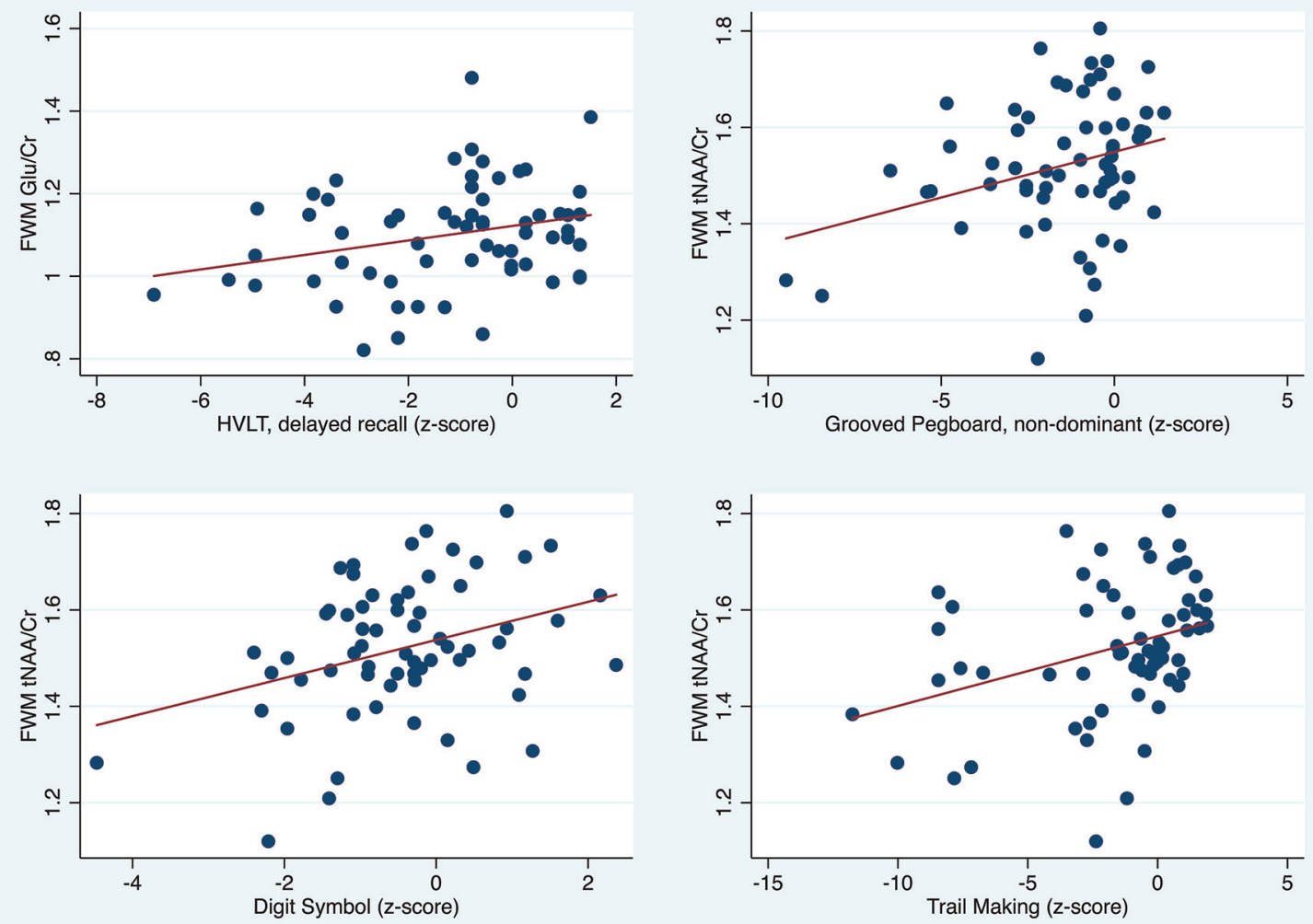

FIG 4. Scatterplots showing significant positive correlations of FWM Glu/Cr with the Hopkins Verbal Learning Test (HVLT) delayed recall, and FWM tNAA/Cr with the Grooved Pegboard non-dominant hand, Digit Symbol, and Trail-Making Test B z scores.
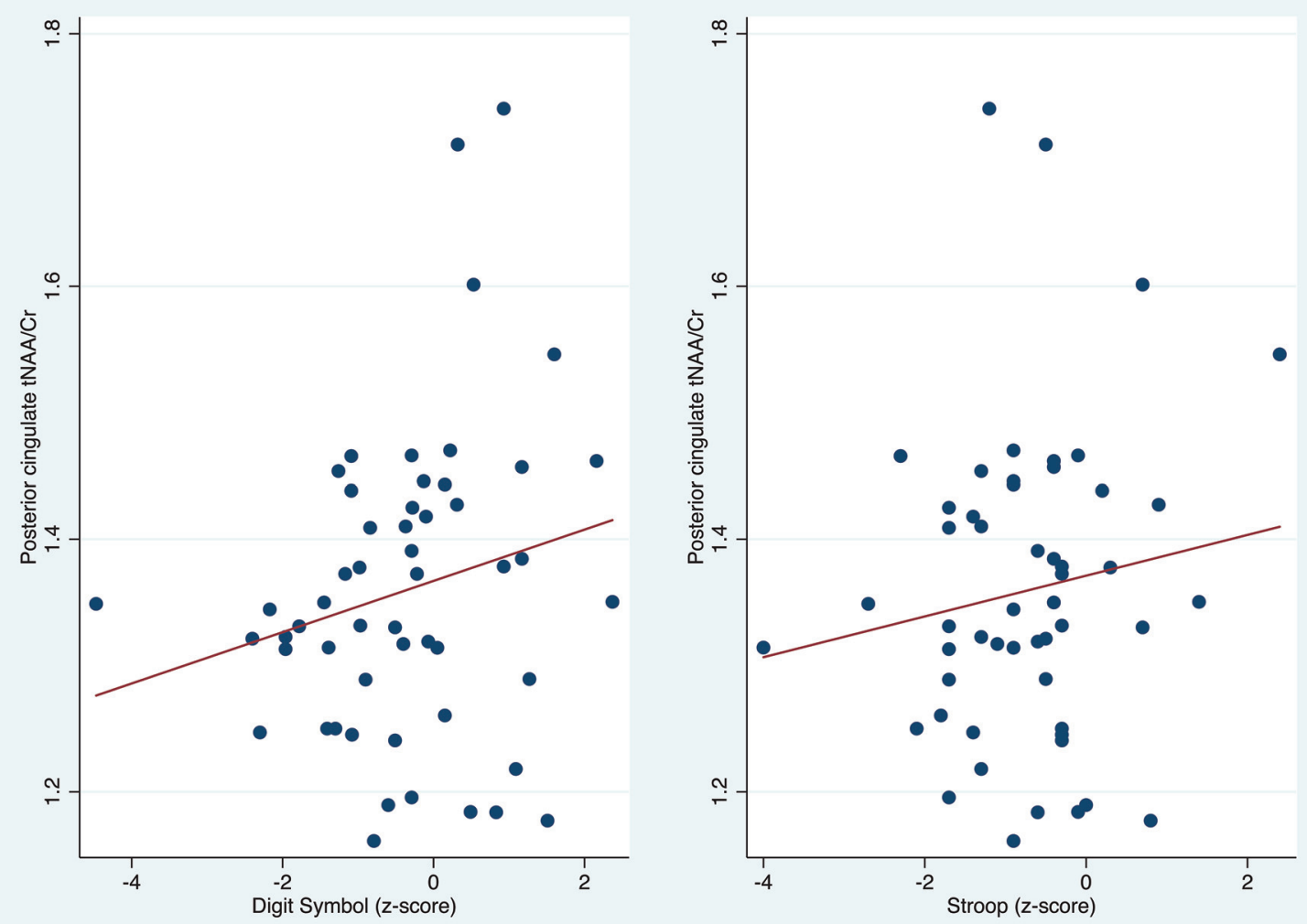

FIG 5. Scatterplots showing significant positive correlation of the posterior cingulate tNAA/Cr with the Digit Symbol and Stroop test $z$ scores. 


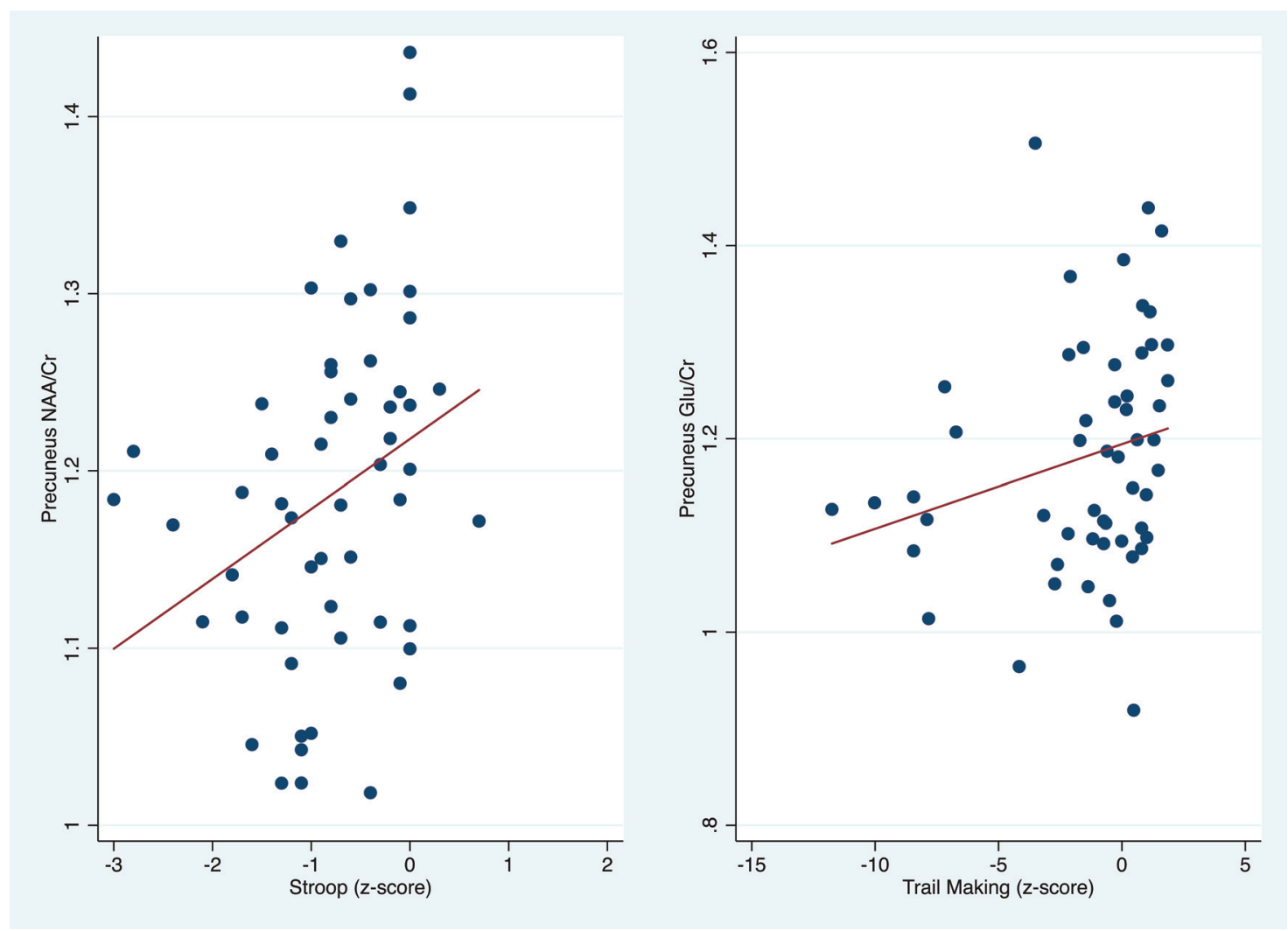

FIG 6. Scatterplots showing significant positive correlation of the precuneus NAA/Cr and Glu/Cr with Stroop test and Trail-Making Part B $z$ scores, respectively.

Regarding correlations between MR spectroscopy results and neuropsychological tests (On-line Table and Figs 4-6), lower FWM tNAA/Cr was associated with worse performance on measures of executive function, fine motor, and psychomotor speed (Trail-Making Test, Part B; Grooved Pegboard Test non-dominant hand; and the Digit Symbol test $(P=.005, .01$, and .001 , respectively). Furthermore, lower FWM Glu/Cr was associated with lower performance on delayed recall on the Hopkins Verbal Learning Test $(P=.02)$ (Fig 4$)$. Lower tNAA/Cr in the posterior cingulate was associated with worse performance on tests of psychomotor speed (Digit Symbol and Stroop Test; $P=.02$ and .04, respectively) (Fig 5). Lower precuneus NAA/Cr was associated with worse performance on the Stroop Test, a test of processing speed $(P=.04)$; while precuneus $\mathrm{Glu} / \mathrm{Cr}$ decreases were associated with worse performance in the Trail-Making Test, Part B, a measure of executive functioning $(P=.04)$ (Fig 6).

\section{DISCUSSION}

The main finding of this study is that 7T MR spectroscopy could find significant differences in metabolite levels between symptomatic and asymptomatic HIV + subjects, with the primary result being lower levels of tNAA (or the ratio tNAA/Cr) in the frontal white matter, posterior cingulate, and precuneus. $\mathrm{Glu} / \mathrm{Cr}$ was also lower in the precuneus in the symptomatic group. In addition, significant correlations were found between FWM measures of tNAA (and tNAA/Cr) and Glu (and Glu/Cr, Glx, and $\mathrm{Glx} / \mathrm{Cr}$ ) and multiple neuropsychological test scores. Posterior cingulate cortex and precuneus measures of NAA and Glu also correlated with performance on the Digit Symbol and Stroop tests. Overall, these results suggest that MR spectroscopy measurements of NAA and glutamate in these brain regions reflect neuroaxonal loss or dysfunction, which correlates with worse performance on neuropsychological tests.

Decreased NAA and Glx (Glu+glutamine) concentrations in HIV infection are well-established from MR spectroscopy studies at lower field strengths; for instance, in 1 study, long TEs performed at $1.5 \mathrm{~T}$ revealed decreased levels of NAA/Cr in the parieto-occipital white matter in asymptomatic HIV + men compared with healthy controls. ${ }^{45} \mathrm{MR}$ spectroscopic imaging studies also performed at long TEs found progressive declines in NAA from HIV-negative controls to asymptomatic and then symptomatic $\mathrm{HIV}+$ patient groups in multiple gray and white matter regions. ${ }^{6,18,46}$ NAA was also found to increase after initiation of cART. ${ }^{6,46}$ Previous $3 \mathrm{~T}$ studies have also reported decreasing Glx concentrations (or Glx/Cr ratios) with increasing symptomatology in HIV infection ${ }^{17,18}$ and decreased levels compared with HIV-negative controls. ${ }^{19}$ Although some 3T studies have used the technique of the TE-averaged point-resolved spectroscopy sequence $^{19}$ to selectively detect Glu, generally it can be difficult to reliably separate Glu from glutamine using conventional MR spectroscopy. Prior studies comparing 7T with lower field strengths have shown improved ability at 7T to quantify Glu and glutamine ${ }^{43}$; the current study at $7 \mathrm{~T}$ confirms that only significant $\mathrm{HIV}$-associated correlations are found for Glu, with no significant associations found for glutamine. NAA and Glu are known to be primarily located in neurons and have been shown in previous studies of various pathologies to decrease when neuronal damage 
occurs. The mechanisms by which neuronal damage occurs in HIV infection are complicated, but it is believed that infiltration of infected macrophages and lymphocytes results in inflammation, astrocytosis, oxidative stress, and synaptodendritic injury. ${ }^{47}$

Several studies performed at 1.5 and $3 \mathrm{~T}$ have reported increased mIns in HIV infection and symptomatic HIV+ subjects compared with asymptomatic subjects. ${ }^{6,19}$ The current study is consistent with these findings. Previous studies at lower field strengths, and usually in younger cohorts of subjects, have generally reported increased levels of mIns in HIV + subjects compared with HIV - controls, with higher mIns in symptomatic HIV+ subjects compared with asymptomatic subjects. ${ }^{18,48}$ The current study did not find strong differences in mIns (or mIns/Cr) between asymptomatic and symptomatic groups in most brain regions, with the exception of slightly lower mIns/Cr in the FWM in the symptomatic group (ie, in the opposite direction to prior findings). ${ }^{18,49}$ There were also few significant positive correlations between high mIns and worse performance on neuropsychological tests. These findings may be due to the older nature of the $\mathrm{HIV}+$ cohort studied here, with a longer disease duration, generally well-controlled viral load, and less neuroinflammation than in previous studies.

Regarding correlations between brain metabolites and neuropsychological test scores, frontal white matter test NAA and Glu measures correlated positively with measures of executive function, motor speed, and verbal and working memory, whereas posterior cingulate cortex and precuneus measures of NAA and Glu predominantly correlated with the Digit Symbol and Stroop tests, measures of working memory and information-processing speed, respectively. The precuneus and posterior cingulate cortex are both visual processing areas, and neuronal dysfunction as measured by the metabolite changes in these areas could contribute to impaired performance in neuropsychological tests, which include visuospatial processing, such as the Digit Symbol and Stroop tests. Specifically, decreased FWM Glu/Cr and Glx were correlated with verbal recall, while posterior cingulate and precuneus Glu Glu/Cr and Glx were associated with attention and working memory and information-processing speed tests. These findings are generally consistent with prior studies performed at 1.5 or $3 \mathrm{~T}$; for instance, in patients receiving cART, significant correlations were found between $3 \mathrm{~T}$ measures of Glu, Glx, and NAA with performance on motor and psychomotor speed, attention, and working memory. ${ }^{6}$

A study performed at $1.5 \mathrm{~T}^{25}$ in $\mathrm{HIV}+$ subjects (most being on cART) assessed motor skills (fine and gross), psychomotor function, information-processing speed, and verbal memory and expressed the results as a composite score NPZ-8 (the average neuropsychological $\mathrm{z}$ scores of 8 different neuropsychological test components). Consistent with the concept of HIV + as a predominantly subcortical dementia, NPZ-8 scores correlated positively with NAA/Cr (and NAA/Cho and NAA/mIns) in the FWM, similar to findings in the current study. Negative correlations in that study were also found between basal ganglia mIns/Cr and NPZ$8 .^{25}$ Another study at $1.5 \mathrm{~T}$ in 45 antiretroviral-naïve HIV + subjects also found elevated frontal white matter mIns and Cho compared with HIV-negative controls, which were correlated with slow performance in fine motor (Grooved Pegboard), psychomo- tor (Trail-Making Test), and executive function (Stroop) tests. ${ }^{50}$ The relative lack of correlations in the current study between neuropsychological test performance and measures of Cho (only PC Cho negatively correlated with the Hopkins Verbal Learning Test delayed recall task) or mIns (PCC mIns/Cr did correlate with performance on the Stroop test) most likely reflects differences in patient populations between the current and previous studies (older HIV+ subjects, all on cART).

Compared with MR spectroscopy at lower field strengths, 7T MR spectroscopy has been shown to offer increased signalto-noise ratios and spectral resolution; however, it also presents some technical challenges, including increased chemical shift dispersion effects, difficulty shimming, and increased radiofrequency power deposition (specific absorption rate). In this study, localized second-order shimming was used to minimize the effects of field inhomogeneity. In addition, the STEAM pulse sequence was used for spatial localization because the $90^{\circ}$ slice-selective pulses in STEAM have excellent slice profiles and low chemical shift dispersion effects and specific absorption rate. ${ }^{51,52}$ However, in the future, other sequences such as semi-LASER and/or MR spectroscopic imaging sequences may be used, which provide higher SNR, spatial resolution, and coverage.

The study also has some limitations; though subjects with overt medical or neurologic abnormalities were excluded, the older HIV + subjects in this study may well have had varying degrees of risk factors commonly encountered in the general population, which contribute to aging and cognitive decline, such as microvascular disease, diabetes, or hypertension. All subjects were taking cART, which is known to affect brain metabolite concentrations. ${ }^{53}$ Although 3D T1WIs were recorded, no volumetric analysis has been performed to date in these subjects because of intensity and contrast variations due to transmit $\mathrm{B}_{1}$ inhomogeneity. However, we do not expect morphometric differences to significantly affect results because metabolite ratios (relative to $\mathrm{Cr}$ ) are relatively insensitive to voxel composition (particularly CSF contamination). Finally, no significant changes were observed in the hippocampus in this study, despite the well-known importance of this structure for memory and other age-related cognitive dysfunction. ${ }^{40,54,55}$ Lack of significant findings may be in part due to the generally lower spectral quality obtained in this region due to magnetic susceptibility effects from bone/air/tissue interfaces proximal to the anterior temporal lobe, as well as partial volume with surrounding tissue due to the small size of the hippocampus. Spectral quality was also lower in the basal ganglia because of the high iron content of the globus pallidus and putamen, which is known to increase line widths in MR spectra from this region ${ }^{56-58}$; this may have also contributed to the lack of significant group differences or neurocognitive correlations detectable in this region.

\section{CONCLUSIONS}

In the older subject population with HIV infection, 7T MR spectroscopy measurements of NAA and Glu may be useful indicators of neuroaxonal loss or dysfunction and correlate with neuropsychological performance. Therefore, 7T MR spectroscopy may be a useful adjunct technique for monitoring disease progression or 
response to therapy in future treatment trials. Other future studies are needed to track longitudinal changes with time, as well as comparisons with HIV-negative control subjects to determine whether cognitive decline and brain metabolite changes occur at a greater rate in $\mathrm{HIV}+$ subjects and whether there are specific metabolic changes only associated with HIV infection in the older population.

Disclosures: Mona Mohamed—RELATED: Grant: National Institutes of Health, Comments: work supported by the National Institutes of Health grant NS081196*. Peter B. Barker-RELATED: Grant: National Institutes of Health*. Richard L. Skolasky-RELATED: Grant: National Institutes of Health*; UNRELATED: Board Membership: North American Spine Society, Comments: member of the Board of Directors; Grants/Grants Pending: National Institutes of Health, Patient Centered Outcomes Research Institute (PCORI); OTHER RELATIONSHIPS: Associate Editor, Quality of Life Research. Ned Sacktor-RELATED: Grant: National Institutes of Health, Comments: work supported by the National Institutes of Health grant NS081196*. *Money paid to the institution.

\section{REFERENCES}

1. Gandhi NS, Skolasky RL, Peters KB, et al. A comparison of performance-based measures of function in HIV-associated neurocognitive disorders. J Neurovirol 2011;17:159-65 CrossRef Medline

2. Kakinami L, de Bruyn G, Pronyk $P$, et al. The impact of highly active antiretroviral therapy on activities of daily living in $\mathrm{HIV}$-infected adults in South Africa. AIDS Behav 2011;15:823-31 CrossRef Medline

3. Schifitto G, Kieburtz K, McDermott MP, et al. Clinical trials in HIVassociated cognitive impairment: cognitive and functional outcomes. Neurology 2001;56:415-18 CrossRef Medline

4. Vivithanaporn P, Heo G, Gamble J, et al. Neurologic disease burden in treated HIV/AIDS predicts survival: a population-based study. Neurology 2010;75:1150-58 CrossRef Medline

5. Sailasuta N, Ross W, Ananworanich J, et al; RV254/SEARCH 010 protocol teams. Change in brain magnetic resonance spectroscopy after treatment during acute HIV infection. PLoS One 2012;7: e49272 CrossRef Medline

6. Lentz MR, Degaonkar M, Mohamed MA, et al. Exploring the relationship of macrophage colony-stimulating factor levels on neuroaxonal metabolism and cognition during chronic human immunodeficiency virus infection. J Neurovirol 2010;16:368-76 CrossRef Medline

7. Letendre S, Marquie-Beck J, Capparelli E, et al; CHARTER Group. Validation of the CNS Penetration-Effectiveness rank for quantifying antiretroviral penetration into the central nervous system. Arch Neurol 2008;65:65-70 CrossRef Medline

8. Clifford DB. HIV-associated neurocognitive disorder. Curr Opin Infect Dis 2017;30:117-22 CrossRef Medline

9. Tozzi V, Balestra P, Bellagamba R, et al. Persistence of neuropsychologic deficits despite long-term highly active antiretroviral therapy in patients with HIV-related neurocognitive impairment: prevalence and risk factors. J Acquir Immune Defic Syndr 2007;45:174-82 CrossRef Medline

10. Harezlak J, Buchthal S, Taylor M, et al; HIV Neuroimaging Consortium. Persistence of HIV-associated cognitive impairment, inflammation, and neuronal injury in era of highly active antiretroviral treatment. AIDS 2011;25:625-33 CrossRef Medline

11. Neuenburg JK, Brodt HR, Herndier BG, et al. HIV-related neuropathology, 1985 to 1999: rising prevalence of HIV encephalopathy in the era of highly active antiretroviral therapy. J Acquir Immune Defic Syndr 2002;31:171-77 CrossRef Medline

12. Valcour V, Paul R, Neuhaus J, et al. The effects of age and HIV on neuropsychological performance. J Int Neuropsychol Soc 2011;17: 190-95 CrossRef Medline

13. Valcour V, Shikuma C, Shiramizu B, et al. Higher frequency of dementia in older HIV-1 individuals: the Hawaii Aging with HIV-1 Cohort. Neurology 2004;63:822-27 CrossRef Medline

14. Van Zijl PC, Barker PB. Magnetic resonance spectroscopy and spec- troscopic imaging for the study of brain metabolism. Ann N Y Acad Sci 1997;820:75-96 CrossRef Medline

15. Chong WK, Sweeney B, Wilkinson ID, et al. Proton spectroscopy of the brain in HIV infection: correlation with clinical, immunologic, and MR imaging findings. Radiology 1993;188:119-24 CrossRef Medline

16. Chang L, Ernst T, Leonido-Yee M, et al. Highly active antiretroviral therapy reverses brain metabolite abnormalities in mild HIV dementia. Neurology 1999;53:782-89 CrossRef Medline

17. Ernst T, Jiang CS, Nakama H, et al. Lower brain glutamate is associated with cognitive deficits in HIV patients: a new mechanism for HIV-associated neurocognitive disorder. J Magn Reson Imaging 2010;32:1045-53 CrossRef Medline

18. Mohamed MA, Barker PB, Skolasky RL, et al. Brain metabolism and cognitive impairment in HIV infection: a 3-T magnetic resonance spectroscopy study. Mag Reson Imaging 2010;28:1251-57 CrossRef Medline

19. Sailasuta N, Shriner K, Ross B. Evidence of reduced glutamate in the frontal lobe of HIV-seropositive patients. NMR Biomed 2009;22: 326-31 CrossRef Medline

20. Menon DK, Ainsworth JG, Cox IJ, et al. Proton MR spectroscopy of the brain in AIDS dementia complex. J Comput Assist Tomogr 1992; 16:538-42 CrossRef Medline

21. Meyerhoff DJ, MacKay S, Poole N, et al. N-acetylaspartate reductions measured by $1 \mathrm{H}$ MRSI in cognitively impaired HIV-seropositive individuals. Magn Reson Imaging 1994;12:653-59 CrossRef Medline

22. Barker PB, Lee RR, McArthur JC. AIDS dementia complex: evaluation with proton MR spectroscopic imaging. Radiology 1995;195: 58-64 CrossRef Medline

23. Laubenberger J, Häussinger D, Bayer S, et al. HIV-related metabolic abnormalities in the brain: depiction with proton MR spectroscopy with short echo times. Radiology 1996;199:805-10 CrossRef Medline

24. Navia BA, Rostasy K. The AIDS dementia complex: clinical and basic neuroscience with implications for novel molecular therapies. Neurotox Res 2005;8:3-24 CrossRef Medline

25. Paul RH, Yiannoutsos CT, Miller EN, et al. Proton MRS and neuropsychological correlates in AIDS dementia complex: evidence of subcortical specificity. J Neuropsychiatry Clin Neurosci 2007;19: 283-92 CrossRef Medline

26. Barker PB, Hearshen DO, Boska MD. Single-voxel proton MRS of the human brain at 1.5T and 3.0T. Magn Reson Med 2001;45:765-69 CrossRef Medline

27. Chang L, Ernst T, St Hillaire C, et al. Antiretroviral treatment alters relationship between MCP-1 and neurometabolites in HIV patients. Antivir Ther 2004;9:431-40 Medline

28. Young AC, Yiannoutsos CT, Hegde M, et al. Cerebral metabolite changes prior to and after antiretroviral therapy in primary HIV infection. Neurology 2014;83:1592-600 CrossRef Medline

29. Tkác I, Oz G, Adriany G, et al. In vivo 1 H NMR spectroscopy of the human brain at high magnetic fields: metabolite quantification at 4T vs. 7T. Magn Reson Med 2009;62:868-79 CrossRef Medline

30. Stephenson MC, Gunner F, Napolitano A, et al. Applications of multi-nuclear magnetic resonance spectroscopy at 7T. World J Radiol 2011;3:105-13 CrossRef Medline

31. Antinori A, Arendt G, Becker JT, et al. Updated research nosology for HIV-associated neurocognitive disorders. Neurology 2007;69: 1789-99 CrossRef Medline

32. Radloff LS. The use of the Center for Epidemiologic Studies Depression Scale in adolescents and young adults. J Youth Adolesc 1991;20: 149-66 CrossRef Medline

33. Giebel CM, Challis D, Montaldi D. The newly revised interview for deteriorations in daily living activities in dementia (R-IDDD2): distinguishing initiative from performance at assessment. Int Psychogeriatr 2017;29:497-507 CrossRef Medline

34. Kaur N, Belchior P, Gelinas I, et al. Critical appraisal of questionnaires to assess functional impairment in individuals with mild 
cognitive impairment. Int Psychogeriatr 2016;28:1425-39 CrossRef Medline

35. Fantoni M, Izzi I, Del Borgo C, et al. Inter-rater reliability of a modified Karnofsky Scale of Performance Status for HIV-infected individuals. AIDS Patient Care STDS 1999;13:23-28 CrossRef Medline

36. Gaines JJ, Shapiro A, Alt M, et al. Semantic clustering indexes for the Hopkins Verbal Learning Test-Revised: initial exploration in elder control and dementia groups. Appl Neuropsychol 2006;13:213-22 CrossRef Medline

37. Shapiro AM, Benedict RH, Schretlen D, et al. Construct and concurrent validity of the Hopkins Verbal Learning Test-revised. Clin Neuropsychol 1999;13:348-58 CrossRef Medline

38. Woods SP, Scott JC, Conover E, et al; HIV Neurobehavioral Research Center Group. Test-retest reliability of component process variables within the Hopkins Verbal Learning Test-Revised. Assessment 2005;12:96-100 CrossRef Medline

39. Chang L, Lee PL, Yiannoutsos CT, et al; HIV MRS Consortium. A multicenter in vivo proton-MRS study of HIV-associated dementia and its relationship to age. Neuroimage 2004;23:1336-47 CrossRef Medline

40. Fjell AM, McEvoy L, Holland D, et al; Alzheimer's Disease Neuroimaging Initiative. What is normal in normal aging? Effects of aging, amyloid and Alzheimer's disease on the cerebral cortex and the hippocampus. Prog Neurobiol 2014;117:20-40 CrossRef Medline

41. Driscoll I, Troncoso JC, Rudow G, et al. Correspondence between in vivo (11)C-PiB-PET amyloid imaging and postmortem, regionmatched assessment of plaques. Acta Neuropathol 2012;124:823-31 CrossRef Medline

42. Öz G, Tkáč I. Short-echo, single-shot, full-intensity 1H MRS for neurochemical profiling at 4T: validation in the cerebellum and brainstem. Magn Reson Med 2011;65:901-10 CrossRef Medline

43. Pradhan S, Bonekamp S, Gillen JS, et al. Comparison of single voxel brain MRS at 3T and 7T using 32-channel head coils. Magn Reson Imaging 2015;33:1013-18 CrossRef Medline

44. Provencher SW. Estimation of metabolite concentrations from localized in vivo proton NMR spectra. Magn Reson Med 1993;30: 672-79 CrossRef Medline

45. Wilkinson ID, Miller RF, Miszkiel KA, et al. Cerebral proton magnetic resonance spectroscopy in asymptomatic HIV infection. AIDS 1997;11:289-95 CrossRef Medline

46. Lentz MR, Kim WK, Kim H, et al. Alterations in brain metabolism during the first year of HIV infection. J Neurovirol 2011;17:220-29 CrossRef Medline
47. McArthur JC, Steiner J, Sacktor N, et al. Human immunodeficiency virus-associated neurocognitive disorders: mind the gap. Ann Neurol 2010;67:699-714 CrossRef Medline

48. Cloak CC, Chang L, Ernst T. Increased frontal white matter diffusion is associated with glial metabolites and psychomotor slowing in HIV. J Neuroimmunol 2004;157:147-52 CrossRef Medline

49. Mohamed MA, Lentz MR, Lee V, et al. Factor analysis of proton MR spectroscopic imaging data in HIV infection: metabolite-derived factors help identify infection and dementia. Radiology 2010;254: 577-86 CrossRef Medline

50. Chang L, Ernst T, Witt MD, et al. Relationships among brain metabolites, cognitive function, and viral loads in antiretroviral-naive HIV patients. Neuroimage 2002;17:1638-48 CrossRef Medline

51. Wijtenburg SA, Rowland LM, Edden RA, et al. Reproducibility of brain spectroscopy at 7T using conventional localization and spectral editing techniques. J Magn Reson Imaging 2013;38:460-67 CrossRef Medline

52. Mekle R, Mlynárik V, Gambarota G, et al. MR spectroscopy of the human brain with enhanced signal intensity at ultrashort echo times on a clinical platform at 3T and 7T. Magn Reson Med 2009;61: 1279-85 CrossRef Medline

53. Sailasuta N, Ananworanich J, Lerdlum S, et al; SEARCH 011 Study Group. Neuronal-glia markers by magnetic resonance spectroscopy in HIV before and after combination antiretroviral therapy. $J$ Acquir Immune Defic Syndr 2016;71:24-30 CrossRef Medline

54. Castellano JF, Fletcher BR, Kelley-Bell B, et al. Age-related memory impairment is associated with disrupted multivariate epigenetic coordination in the hippocampus. PLoS One 2012;7:e33249 CrossRef Medline

55. Castellano JF, Fletcher BR, Patzke H, et al. Reassessing the effects of histone deacetylase inhibitors on hippocampal memory and cognitive aging. Hippocampus 2014;24:1006-16 CrossRef Medline

56. Daugherty A, Raz N. Age-related differences in iron content of subcortical nuclei observed in vivo: a meta-analysis. Neuroimage 2013; 70:113-21 CrossRef Medline

57. Haacke EM, Miao Y, Liu M, et al. Correlation of putative iron content as represented by changes in $\mathrm{R} 2 *$ and phase with age in deep gray matter of healthy adults. J Magn Reson Imaging 2010;32:561-76 CrossRef Medline

58. Persson N, Wu J, Zhang Q, et al. Age and sex related differences in subcortical brain iron concentrations among healthy adults. $\mathrm{Neu}$ roimage 2015;122:385-98 CrossRef Medline 